\title{
Aportació metodològica per al càlcul de la Petjada Ecològica a nivell municipal
}

Clara Montaner Augé ${ }^{1}$ | Xavier Mayor Farguell 2

Rebut: 13-06-2019 | en la seva versió final: 18-05-2020

Resum

\begin{abstract}
Actualment es desconeix la magnitud dels impactes que es produeixen a escala municipal. Avançar en l'estimació de la Petjada Ecològica (PE) a escales reduïdes és rellevant, ja que aquest indicador és eficaç per orientar polítiques ambientals i per avaluar el grau d'efectivitat de les estratègies implementades. L'objectiu d'aquesta investigació és determinar, en el context dels 36 municipis de l’Àrea Metropolitana de Barcelona (AMB), quins factors socioeconòmics possibiliten una estimació ajustada de les variables del càlcul de la PE, concretament, la petjada associada al consum de productes manufacturats. La metodologia s'ha basat en: (1) caracteritzar aquests municipis segons patrons de similituds i diferències per diversos factors socioeconòmics (dades: de l'Institut d'Estadística de Catalunya, de l'AMB i de la Diputació de Barcelona); (2) analitzar en base a fonts especialitzades en PE quins factors s'ajusten millor per estimar la PE dels productes manufacturats a nivell municipal. La classificació de municipis en grups mostra uns patrons que determinen diferents pautes de consum de recursos. Es conclou que la PE associada al consum de productes manufacturats a nivell municipal es pot estimar utilitzant dos factors de conversió: la Renda Familiar Disponible Bruta, per estimar les importacions; i el Valor Afegit Brut del sector industrial, per estimar les exportacions. La metodologia que aquí es desenvolupa és útil per a administracions locals i per a professionals del planejament estratègic i de la gestió per a la sostenibilitat.
\end{abstract}

Paraules clau: petjada ecològica; diagnosi territorial; Àrea Metropolitana de Barcelona

Citació

Montaner Augé, C. y Mayor Farguell, X. (2020). Aportació metodològica per al càlcul de la Petjada Ecològica a nivell municipal. ACE: Architecture, City and Environment, 15(43), 9519. DOI: http://dx.doi.org/10.5821/ace.15.43.9519

\footnotetext{
1 Llicenciada en Ciències ambientals, UB, Màster en Planificació urbana i Sostenibilitat, FPC-UPC. Consultora ambiental a IRBIS; Redactora a Calaix Ambiental. ${ }^{2}$ Doctor en Biologia, Màster en Ecologia, UAB i Màster en Tecnologia i Gestió Ambiental, UPC. Soci fundador i director d'IRBIS (Scopus Author ID: 7801685910). Correu de contacte: claramontaner13@gmail.com
} 


\title{
Methodological contribution for calculating Ecological Footprint at a municipal level
}

\begin{abstract}
Currently the extent of impacts occurring at the municipal level is unknown. Advancing small-scale Ecological Footprint (EF) estimation is relevant as this indicator is useful to guide environmental policies and for evaluating the effectiveness of implemented strategies. This investigation aims to the development of an estimation methodology of the EF of consumption associated to manufactured goods at a municipal level, in the Barcelona Metropolitan Area context. The applied methodology includes: (1) a characterization of the municipalities by types defined according to socioeconomic similarities and differences; (2) analyse which factors are best suited for estimating EF of municipal manufactured products, according to specialized PE sources. The resulting clusters of municipalities follow different patterns associated with specific consumption levels. The study concludes that the EF associated with the consumption of manufactured goods at the municipal level can be estimated using two conversion factors: Gross Available Family Income, to estimate imports; and Gross Value Added of the industrial sector, to estimate the exports. The methodology developed here can serve local administrations and other land managers, as well as planning professionals and sustainability managers.
\end{abstract}

Keywords: ecological footprint; territorial diagnosis; Barcelona Metropolitan Area

\section{Introducció}

\subsection{El concepte de Petjada Ecológica (PE)}

El creixement de la població mundial i el continu increment en el consum d'energia i materials i en la generació de residus caracteritzen els sistemes socioeconòmics actuals. Per contra, la capacitat productiva dels ecosistemes i els serveis que proveeixen són finits. Com a conseqüència d'aquest desequilibri, els efectes de l'activitat humana sobre el medi ambient cada cop són més manifestos.

Per tal d'avaluar l'estat dels ecosistemes i la magnitud dels impactes ambientals que es donen a causa de l'actual interacció humana amb el medi, s'utilitzen indicadors ambientals com a instruments de valoració. Un indicador ambiental és la Petjada Ecològica (en endavant PE), que mesura quin és l'abast territorial dels impactes que una determinada població genera sobre els ecosistemes per tal de mantenir el seu nivell de vida (Wackernagel i Rees, 1996).

El concepte de PE, desenvolupat per Mathis Wackernagel i William Rees el 1996 i recollit en el llibre Our Ecological Footprint, es defineix com el total de superfície "ecològicament productiva" necessària per produir els recursos consumits per una certa comunitat humana, així com la

ACE, 15 (4:3) CC BY-ND 3.0 ES | UPC Barcelona, España | Aportació metodològica per al càlcul de la Petjada 
superfície necessària per absorbir tots els residus que genera, de manera indefinida en el temps (Wackernagel i Rees, 1996). És un indicador de sostenibilitat que expressa l'impacte humà sobre el territori per al consum de recursos i la generació de residus, en termes de quina és l'àrea total requerida a fi de suportar una pauta de consum d'una determinada població (Ewing et al., 2010a).

En el context més proper, la PE s'ha calculat per l'estat espanyol per al període 1990-2005, obtenint-se un valor de 6,4 gha1 per habitant per a l'any 2005 (Gullón i Esteban, 2008); per Catalunya en els anys 2003 i 2005, on els resultats van ser respectivament de 3,92 ha per habitant (Mayor, Quintana i Belmonte, 2005) i 4,58 gha per habitant (Mayor et al., 2006); i per Barcelona ciutat el 1996, un càlcul en cert sentit pioner, amb un resultat de 3,23 ha per habitant (Relea i Prat, 1998)².

En els càlculs de PE es tenen en compte diversos factors que impliquen una utilització de la superfície productiva dels ecosistemes: consum de recursos agrícoles, consum de les pastures, consum de recursos pesquers, consum de productes manufacturats, consum d'energia i consum de sòl per a la construcció. Donat que el càlcul d'aquests factors és un treball molt vast, aquesta investigació es centra en una d'aquestes variables: el consum de productes manufacturats.

\subsection{Objectius}

L'objectiu d'aquesta investigació és determinar quins factors socioeconòmics poden contribuir de manera més ajustada a l'estimació de les variables del càlcul de la PE a escala municipal (concretament la variable del consum de productes manufacturats). L'àmbit estudiat inclou els 36 municipis de l'Àrea Metropolitana de Barcelona (AMB). L'AMB és un territori amb una important població i activitat econòmica en el context de Catalunya, per tant, també presenta una considerable incidència pel que fa al consum de recursos. Això fa que aquest àmbit sigui un territori especialment adient per enfrontar el càlcul de la seva PE.

\subsection{Introducció al càlcul de la PE associada al consum de productes manufacturats}

La PE total associada al consum d'una població és igual a la PE associada a la producció dels béns consumits, més l'associada a les importacions, restant-hi l'associada a les exportacions (Galli et al., 2007; Ewing et al., 2010b), segons la següent fórmula de càlcul de la PE total:

PE consum = PE producció + PE importacions - PE exportacions

Tanmateix, per al càlcul de la PE associada al consum de productes manufacturats les emissions generades en les diferents fases de producció no es consideren, perquè ja queden computada en altres factors. És a dir, les primeres matèries comptabilitzen en aquelles superfícies bioproductives que les hagin produït i la PE de la seva fabricació queda inclosa en el consum d'electricitat i altres combustibles del territori analitzat (Galli et al., 2007; Ewing et al., 2010b). Per tant, només es computa la PE del comerç d'aquest producte, que es calcula en base a l'energia consumida en el seu transport, sumant-la si s'ha importat i restant-la si s'ha exportat. Així, la fórmula de càlcul de la PE associada al consum de productes manufacturats queda simplificada com:

$$
\mathrm{PE} \text { consum }=\mathrm{PE} \text { importacions }-\mathrm{PE} \text { exportacions }
$$

\footnotetext{
${ }^{1}$ Les unitats de mesura de la PE són les global hectàrees (gha). Una gha és una hectàrea biològicament productiva estàndard, calculada a partir de la productivitat mundial mitjana d'un determinat any. El seu objectiu és fer els càlculs de PE comparables entre territoris i països (Galli et al., 2007).

2 Als estudi del càlcul de la PE de Catalunya per al 2003 i de Barcelona per al 1996, no es va realitzar la transformació d'hectàrees a global hectàrees. Els resultats transformats serien de l'ordre de 4,7 gha i 3,9 gha, respectivament.
}

ACE, 15 (4:3) CC BY-ND 3.0 ES | UPC Barcelona, España | Aportació metodològica per al càlcul de la Pețada 


\section{Metodologia}

\subsection{Un enfoc de càlcul tipus top-down}

A l'hora de quantificar el consum de sòl implicat en cada un dels grups què inclouen els càlculs de PE, es poden utilitzar dos enfocs diferents: l'enfoc de baix a dalt (bottom-up) i l' enfoc de dalt a baix (top-down). Amb l'enfoc bottom-up es calcula la PE total d'un país o regió sumant la PE del conjunt de productes individuals consumits per la població estudiada (Moore et al., 2013).

Els plantejaments top down s'utilitzen principalment en situacions amb una certa manca de dades, com sol succeir per a escales sub-nacionals (Moore et al., 2013). Es parteix de valors de PE d'àmbits territorials més grans que l'àmbit analitzat i s'utilitzen variables que permetin estimar quina part del consum recau en la subpoblació a estudiar. És a dir, s'ajusta el consum de l'àmbit territorial superior segons s'estimin les diferències entre el consum per càpita a l'àmbit general i a l'àmbit reduït (Moore et al., 2013). Diversos estudis realitzats per la institució de referència en matèria de PE, la Global Footprint Network, demostren que la PE d'una ciutat es relaciona amb diverses característiques socioeconòmiques, ambientals i urbanístiques (Galli et al., 2007; Moore et al., 2013).

En la present investigació s'ha emprat un procediment de càlcul tipus top down, en resposta a la limitació de dades disponibles per la dimensió municipal. Per tant, es requereixen diversos factors de conversió que permetin extrapolar els diferents tipus de consum que componen els càlculs de PE al nivell municipal a partir de xifres disponibles a escales més grans.

Es parteix de la hipòtesi que es pot determinar un indicador (per exemple, població, densitat, renda per càpita, generació de residus, etc.) que sigui adequat per a extrapolar la dada de PE associada al consum de productes manufacturats d'una escala més gran. D'aquesta manera, es pot estimar quina proporció del consum de productes manufacturats de l'àmbit més general recau a cada municipi. La fórmula del factor de conversió proposat per al càlcul estimat del consum de béns manufacturats a nivell municipal, a utilitzar s'expressa:

$$
\frac{\text { PE del consum de productes municipal }}{\text { PE del consum de productes a l'AMB }}=\frac{\text { Valor de l'indicador al municipi }}{\text { Valor de l'indicador a l'AMB }}
$$

Les dades emprades s'han extret de l'Institut d'Estadística de Catalunya (administració de Catalunya), de l'Àrea Metropolitana de Barcelona (administració metropolitana) i de la Diputació de Barcelona (administració provincial). D'entre les dades que es troben disponibles desagregades pels municipis de l'AMB s'han seleccionat aquelles variables que compleixen:

- Aporten informació indicativa en relació al nivell de consum de béns.

- La seva interpretació és clara i no críptica.

- No aporten informació redundant respecte alguna altra variable. S'ha considerat una variable redundant si, a l'hora de ser analitzada amb alguna altra variable mitjançant gràfics de dispersió (utilitzant fulls de càlcul Excel), s'obtenen correlacions reflectides en coeficients de determinació iguals o superiors a 0,80.

Les variables seleccionades han estat 10: (1) Població censada, (2) Població estacional, (3) Densitat, (4) Producte Interior Brut per habitant (en endavant PIB), (5) Renda Familiar Disponible Bruta per habitant (en endavant RFDB), (6) Valor Afegit Brut del sector industrial, (7) Valor Afegit Brut dels serveis, (8) Valor Afegit Brut de la construcció, (9) Generació de residus domèstics, (10) Abundància de bars i restaurants. Els Valors Afegits Bruts dels diferents sectors s'han incorporat a les anàlisis 
posteriors expressats en percentatges sobre el Valor Afegit Brut ${ }^{3}$ total de cada municipi. L'estudi s'ha desenvolupat en dues fases: una fase inicial de caracterització dels municipis metropolitans, per tal de conèixer els diferents perfils presents i quina influència exerceixen les variables emprades en quant a la definició de grups; i una segona fase d'elecció d'indicadors.

\subsection{Procés de caracterització de municipis}

En aquesta fase s'han classificat els municipis en grups per similituds en els seus trets, estructura i qualitats. Per fer-ho, s'han emprat dos mètodes diferents: (A) per una banda, s'han utilitzat mètodes de classificació qualitatius i, per una altra, (B) mètodes de classificació estadístics.

\section{A. Desenvolupament de la caracterització qualitativa}

La classificació qualitativa s'ha desenvolupat a partir de la formació de grups de municipis en relació a parelles de variables (gràfics de dispersió amb el programa Excel). Aquests grups s'ha superposat per definir els grups finals, on s'han prioritzat les agrupacions més clares i recurrents, deixant en segon terme aquelles dades que disminuïen la homogeneïtat dins dels grups.

B. Desenvolupament de la caracterització a partir de mètodes estadístics

La caracterització estadística s'ha desenvolupat mitjançant el software estadístic Ginkgo, basada en:

- Un estudi de la matriu de correlació de Pearson per conèixer les relacions entre variables.

- La classificació de municipis en grups mitjançant el mètode d'ordenació de matrius de distàncies k-means (classificació en clústers). Aquesta classificació s’ha complementat amb un estudi de les components principals, a fi de conèixer quins són els factors que aporten informació més decisiva a l'hora de situar els municipis en l'espai multidimensional.

\subsection{Recerca documental sobre factors socioeconómics indicatius del consum de béns manufacturats}

Per tal de seleccionar quins factors socioeconòmics són més adequats per esdevenir indicadors de la PE associada consum de béns manufacturats, s'ha efectuat una recerca bibliogràfica amb l'objectiu de contrastar quines variables s'hi relacionen de manera directa i quines d'elles han estat emprades en experiències de càlcul similars.

La documentació utilitzada prové de les següents fonts:

- L'associació de referència sobre PE, la Global Footprint Network (GFN): per conèixer les variables socioeconòmiques que són determinants dels nivells de consum personal de béns, energia, serveis i espai, de manera que delimiten la PE.

- 6 estudis de PE en territoris reduïts ${ }^{4}$ de diferents continents: per comparar els factors de càlcul utilitzats en deferents metodologies de càlcul tipus top-down.

- Diferents calculadores de PE personal a la xarxa5: analitzant quines variables tenen en compte per al seu procediment de càlcul.

- Enquesta de Pressupostos Familiars de 2012 de l'Instituto Nacional de Estadística d'Espanya: per estudiar la relació entre una sèrie de variables i els nivells de despesa familiar.

\footnotetext{
3 El Valor Afegit Brut es defineix d'acord a l'Institut d'Estadística de Catalunya com la "Riquesa generada durant el període considerat que s'obté per diferència entre el valor de la producció i els consums intermedis utilitzats".

${ }^{4}$ Els articles consultats han estudiat la PE de: California, Estats Units (Moore el al., 2013); San Francisco, Estats Units (Moore i GFN, 2011); Quito, Ecuador (Moore i Stechbart, 2011); Ontario, Canadà (Stechbart i Wilson, 2010); Calgary, Canadà (The City of Calgary, 2007); i Gènova, Itàlia (Provincia di Genova, 2005).

${ }^{5}$ Les calculadores de PE consultades han estat de les següents organitzacions:la ONG internacionl Global Footprint Network (GFN); la ONG internacional World Wildlife Fundation (WWF); l'oficina administrativa Environment Protection Authority (EPA) de l'estat de Victòria, Austràlia; l'assessoria ambiental nord-americana Center for Sustainable Economy; l'assessoria ambiental espanyola Miliarium.com Ingeniería Civil y Medio Ambiente; i l'associació sense ànim de lucre espanyola Organización de Consumidores y Usuarios (OCU).
} 


\section{Resultats}

\subsection{Caracterització dels municipis}

\section{A. Grups obtinguts pel mètode qualitatiu}

La classificació s'ha centrat en 8 de les 10 variables seleccionades: Població censada, Població estacional, Densitat, PIB, RFDB, Valor Afegit Brut industrial, Valor Afegit Brut dels serveis, i Valor Afegit Brut de la construcció. Mentre que les dues variables que aportaven més heterogeneïtat als grups s'han deixat en segon terme: Generació de residus domèstics i Abundància de restaurants i bars. Els 7 grups obtinguts es mostren a la Taula 1.

Taula 1. Grups de municipis obtinguts pel mètode qualitatiu.

\begin{tabular}{|c|c|}
\hline \multicolumn{2}{|c|}{ 1. Municipis marcadament metropolitans } \\
\hline $\begin{array}{l}\text { Badalona } \\
\text { Cornellà de Llobregat } \\
\text { L'Hospitalet de Llobregat } \\
\text { Sant Adrià del Besòs } \\
\text { Sta. Coloma de Gramenet }\end{array}$ & 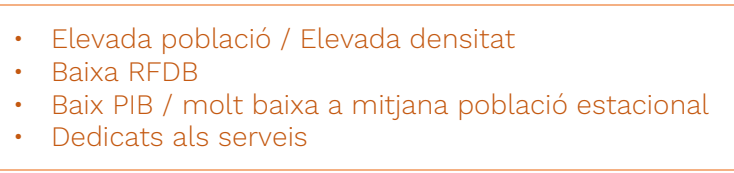 \\
\hline \multicolumn{2}{|c|}{ 2. Municipis dependents de les infraestructures de comunicació o d'altres centres potents } \\
\hline $\begin{array}{l}\text { Barberà del Vallès } \\
\text { Montcada i Reixac } \\
\text { Montgat (*) } \\
\text { Sant Andreu de la Barca } \\
\text { Sant Vicenç dels Horts } \\
\left.\text { Ripollet }{ }^{*}\right)\end{array}$ & $\begin{array}{l}\text { - Mitjana-baixa població / Mitjana densitat (excepte } \\
\text { Ripollet) } \\
\text { - Baixa a mitjana RFDB } \\
\text { - Mig PIB / mitjana (o baixa) població estacional } \\
\text { - La majoria industrials }\end{array}$ \\
\hline \multicolumn{2}{|c|}{ 3. Municipis tipus Baix Llobregat } \\
\hline $\begin{array}{l}\text { Castelldefels } \\
\text { El Prat del Llobregat(*) } \\
\text { Gavà } \\
\text { Sant Boi de Llobregat } \\
\text { Sant Feliu de Llobregat } \\
\text { Viladecans }\end{array}$ & $\begin{array}{l}\text { - Elevada població / Mitjana densitat } \\
\text { - } \text { Baixa RFDB } \\
\text { - } \text { Mig-baix PIB / mitjana-baixa població estacional } \\
\text { - De serveis o una mica industrials }\end{array}$ \\
\hline \multicolumn{2}{|c|}{ 4. Municipis urbans amb un cert poder adquisitiu } \\
\hline $\begin{array}{l}\text { Cerdanyola del Vallès } \\
\text { Esplugues de Llobregat } \\
\text { Molins de Rei } \\
\text { Sant Joan Despí }\end{array}$ & $\begin{array}{l}\text { - Mitjana-elevada població / Mitjana densitat } \\
\text { - Mitjana-elevada RFDB } \\
\text { - Mig-elevat PIB / mitjana-elevada població estacional } \\
\text { - De serveis, una mica industrials }\end{array}$ \\
\hline \multicolumn{2}{|c|}{ 5. Municipis d'elevat poder adquisitiu } \\
\hline $\begin{array}{l}\text { Sant Cugat del Vallès } \\
\text { Sant Just Desvern }\end{array}$ & $\begin{array}{l}\text { - Elevada a baixa població / Baixa densitat } \\
\text { - Elevada RFDB } \\
\text { - Elevat PIB / elevada població estacional } \\
\text { - De serveis, una mica industrials }\end{array}$ \\
\hline \multicolumn{2}{|c|}{ 6. Municipis marcadament residencials } \\
\hline $\begin{array}{l}\text { Begues } \\
\text { Corbera de Llobregat } \\
\text { Tiana } \\
\text { Torrelles de Llobregat }\end{array}$ & $\begin{array}{l}\text { - } \text { Baixa població / Baixa densitat } \\
\text { - Mitjana-elevada RFDB } \\
\text { - Molt baix PIB / baixa a mitjana població estacional } \\
\text { - } \text { Destaca el sector de la construcció }\end{array}$ \\
\hline \multicolumn{2}{|l|}{ 7. Municipis tipus poble } \\
\hline $\begin{array}{l}\text { Castellbisbal }\left(^{\star}\right) \\
\text { Cervelló } \\
\text { Pallejà } \\
\text { Sta. Coloma de Cervelló } \\
\text { El Papiol } \\
\text { La Palma de Cervelló } \\
\text { Sant Climent de Llobregat }\end{array}$ & $\begin{array}{l}\text { - Baixa població / Baixa densitat } \\
\text { - Baixa RFDB } \\
\text { - Baix PIB/baixa-mitjana població estacional (excepte } \\
\text { Castellbisbal) } \\
\text { - Pes dels serveis variats }\end{array}$ \\
\hline
\end{tabular}

Font: Elaboració pròpia. 
Els municipis senyalats amb un asterisc $\left(^{*}\right)$ es diferencien dels municipis de la resta del grup en alguna o algunes de les seves dades. Per altra banda, hi ha dos municipis que, per les seves característiques singulars, no s'han agrupat amb la resta. Són: Badia del Vallès per la seva baixa població però molt elevada densitat i una RFDB molt baixa; i Barcelona, ja que presenta un població i una densitat molt elevades, però es diferencia dels municipis classificats com a metropolitans en que tant la RFDB com el PIB per càpita són elevats.

\section{B. Grups obtinguts a partir de mètodes estadístics}

A partir dels valors transformats i estandarditzats s'ha construït, en primer lloc, la matriu de correlació de Pearson, que es mostra a la Taula 2. En gris clar es ressalten les correlacions mitjanes i en gris fosc les correlacions elevades.

Taula 2. Matriu de correlació de Pearson per a les variables estudiades

\begin{tabular}{|c|c|c|c|c|c|c|c|c|c|c|}
\hline & POB & PoEs & DENS & PIB & RFDB & RESID & REST & VABi & VABC & VABs \\
\hline POB & 1,00 & & & & & & & & & \\
\hline PoEs & 0,29 & 1,00 & & & & & & & & \\
\hline DENS & 0,75 & $-0,07$ & 1,00 & & & & & & & \\
\hline PIB & 0,41 & 0,76 & 0,21 & 1,00 & & & & & & \\
\hline RFDB & $-0,07$ & 0,27 & $-0,37$ & 0,14 & 1,00 & & & & & \\
\hline RESID & 0,25 & $-0,14$ & 0,49 & 0,01 & $-0,41$ & 1,00 & & & & \\
\hline REST & 0,31 & 0,50 & 0,01 & 0,39 & 0,40 & $-0,14$ & 1,00 & & & \\
\hline VABi & $-0,09$ & 0,34 & $-0,09$ & 0,59 & 0,11 & 0,09 & 0,25 & 1,00 & & \\
\hline VABC & $-0,48$ & $-0,65$ & $-0,34$ & $-0,83$ & $-0,07$ & $-0,11$ & $-0,33$ & $-0,45$ & 1,00 & \\
\hline VABs & 0,46 & $-0,02$ & 0,37 & $-0,19$ & $-0,04$ & 0,06 & $-0,06$ & $-0,83$ & $-0,03$ & 1,00 \\
\hline
\end{tabular}

Nota: Els valors mitjans (valors entre $\pm 0,3$ i $\pm 0,59$ ) es troben remarcats en gris clar; els valors elevats (valors majors de $\pm 0,60$ ) en gris fosc. Els acrònims de les variables són: Població censada (POB), Població estacional (PoEs), Densitat (DENS), Producte Interior Brut per habitant (PIB), Renda Familiar Disponible Bruta per habitant (RFDB) Valor Afegit Brut del sector industrial (VABi), Valor Afegit Brut dels serveis (VABs), Valor Afegit Brut de la construcció (VABC), Generació de residus domèstics (RESID), Abundància de bars i restaurants (REST).

Font: Elaboració pròpia a partir de les fonts estadístiques vàries citades a l'apartat 2 del present article.

Mitjançant la classificació en clústers pel mètode k-means s’ha obtingut la següent classificació de municipis en 4 grups. A la Taula 3 es mostren els quatre grups obtinguts d'acord als valors mostrats respecte a les tres components principals trobades. Per les seves qualitats, se'ls ha donat els noms de: G1. Municipis intermedis, G2. Municipis més metropolitans, G3. Municipis tipus poble i G4. Municipis amb centralitat.

En l'anàlisi de components principals s'ha obtingut que amb les següents components s'explica el $77,12 \%$ de la informació, les quals venen definides en relació a les següents variables (“+” si la proporcionalitat és directa, "-" si la proporcionalitat és inversa):

(1) La primera component es pot definir com l'Atracció que generen els municipis (recull el 34,34\% de la informació). Ve explicada per la combinació de les variables: +Població estacional, +PIB, +Abundància de Restaurants, +Valor Afegit Brut industrial, -Valor Afegit Brut comercial.

(2) La segona component es pot entendre com el caràcter metropolità, o la Metropolitanitat dels municipis (recull el 25,82\% de la informació). Queda definida mitjançant les variables: +Població censada, +Densitat, +Generació de residus domèstics, +Valor Afegit Brut dels serveis, -Valor Afegit Brut industrial, -RFDB.

ACE, 15 (4:3) CC BY-ND 3.0 ES | UPC Barcelona, España | Aportació metodològica per al càlcul de la Petjada 
(3) La tercera component ve donada pels Sectors económics dels municipis (explica el 16,96\% de la informació) i ve definida segons: +Valor Afegit Brut industrial, +Generació de residus domèstics, -RFDB, - Valor Afegit Brut dels serveis.

Taula 3. Grups de municipis obtinguts a través de mètodes estadístics i els seus respectius valors per a les components principals trobades

\begin{tabular}{|c|c|c|c|}
\hline & Pc-1 Atracció & PC-2 Metropolitanitat & PC-3 Sectors econòmics \\
\hline $\begin{array}{l}\text { G1. Municipis intermedis } \\
\text { Barberà del Vallès } \\
\text { Castellbisbal } \\
\text { Esplugues de Llobregat } \\
\text { Gavà } \\
\text { Molins de Rei } \\
\text { Montcada i Reixac } \\
\text { Sant Adrià del Besòs } \\
\text { Sant Andreu de la Barca } \\
\text { Sant Feliu de Llobregat } \\
\text { Sant Joan Despí } \\
\text { Sant Vicenç dels Horts }\end{array}$ & $\begin{array}{l}\qquad(+a++) \\
{[0,03<3,76]} \\
\text { Valors força variables } \\
\text { però en tots casos } \\
\text { de signe positiu. }\end{array}$ & $\begin{array}{l}\qquad(-\mathrm{a} \approx 0) \\
{[-3,01<0,49]} \\
\text { Valors més aviat de } \\
\text { signe negatiu. }\end{array}$ & $\begin{array}{c}\qquad(+) \\
{[-0,18<1,70]} \\
\text { S’hi troben els valors per } \\
\text { a aquesta component } \\
\text { més elevats. }\end{array}$ \\
\hline $\begin{array}{l}\text { G2. Municipis més metropolitans } \\
\text { Badalona } \\
\text { Badia del Vallès } \\
\text { Cornellà de Llobregat } \\
\text { Hospitalet de Llobregat } \\
\text { Ripollet } \\
\text { Sant Boi de Llobregat } \\
\text { Santa Coloma de Gramenet } \\
\text { Viladecans }\end{array}$ & $\begin{array}{l}\qquad(-\mathrm{a} \approx 0) \\
{[-2,97<0,17]} \\
\text { Valors més aviat de } \\
\text { signe negatiu }\end{array}$ & $\begin{array}{c}\qquad(++) \\
{[1,00<3,58]} \\
\text { Valors elevats }\end{array}$ & $\begin{array}{l}\qquad(\approx 0) \\
{[-0,09<1,51]} \\
\text { La gran majoria molt } \\
\text { propers a zero }\end{array}$ \\
\hline $\begin{array}{l}\text { G3. Municipis tipus poble } \\
\text { Begues } \\
\text { Cervelló } \\
\text { Corbera de Llobregat } \\
\text { Montgat } \\
\text { La Palma de Cervelló } \\
\text { Pallejà } \\
\text { El Papiol } \\
\text { Sant Ciment de Llobregat } \\
\text { Santa Coloma de Cervelló } \\
\text { Tiana } \\
\text { Torrelles de Llobregat }\end{array}$ & $\begin{array}{c}(--) \\
{[-3,06<-0,57]} \\
\text { Valors força } \\
\text { homogenis i tots } \\
\text { negatius }\end{array}$ & $\begin{array}{c}(--) \\
{[-2,52<-0,56]} \\
\text { Valors força } \\
\text { homogenis i tots } \\
\text { negatius }\end{array}$ & $\begin{array}{c}\quad(-\mathrm{a} \approx 0) \\
{[-2,15<0,90]} \\
\begin{array}{c}\text { Valors més aviat } \\
\text { negatius }\end{array}\end{array}$ \\
\hline $\begin{array}{l}\text { G4. Municipis amb centralitat } \\
\text { Barcelona } \\
\text { Castelldefels } \\
\text { Cerdanyola del Vallès } \\
\text { El Prat de Llobregat } \\
\text { Sant Cugat del Vallès } \\
\text { Sant Just Desvern }\end{array}$ & $\begin{array}{c}\qquad(++) \\
{[1,50<3,20]} \\
\text { Valors alts excepte } \\
\text { Castelldefels, }\{-0,44\}\end{array}$ & $\begin{array}{c}\qquad(-\mathrm{a}+) \\
{[-1,88<2,38]} \\
\text { Valors força variables }\end{array}$ & $\begin{array}{c}\qquad(--) \\
{[-3,06<1,06]} \\
\text { Valors molt negatius }\end{array}$ \\
\hline
\end{tabular}

Font: Elaboració pròpia a partir de les fonts estadístiques vàries citades a l'apartat 2 del present article.

A continuació es mostren tres gràfics (Figures 1, 2 i 3) on es situen els grups de municipis generats en l'anàlisi de $k$-means en un pla format per les components principals obtingudes com a eixos d'abscisses i d'ordenades.

A la Figura 1 s'aprecien els quatre grups de municipis distribuïts, d'esquerra a dreta, de més actius i atractors a menys i, de baix a dalt, de municipis més densos i poblats a menys. A l'hora d'interpretar el gràfic, cal tenir en compte que els eixos corresponents a la Pc-1, Atracció, i a la Pc-2, Metropolitanitat, s'han de llegir de dreta a esquerra i de dalt a baix, és a dir, situant els municipis amb valors màxims segons aquest dos eixos a l'esquerra i a baix. L'orientació d'aquests eixos ha vingut donada pel programa estadístic. 
Aquest gràfic permet observar molt nítidament com el Grup 3. Municipis tipus poble es desmarca de la resta, situant-se a la cantonada superior dreta, on apunta el Valor Afegit Brut de la construcció, al contrari de tota la resta de variables.

Aquest grup es caracteritza per una baixa Metropolitanitat així com per una baixa Atracció. La resta de grups no són tan homogenis, però s'observa el caràcter de grup de valors mitjans del Grup 1. Municipis intermedis, la Metropolitanitat però poca Atracció del Grup 2. Municipis més metropolitans i l'elevada Atracció amb una Metropolitanitat variable del Grup 4. Municipis amb centralitat.

Figura 1. Gràfic de correlació amb les components principals Pc-1 Atracció i Pc-2 Metropolitanitat

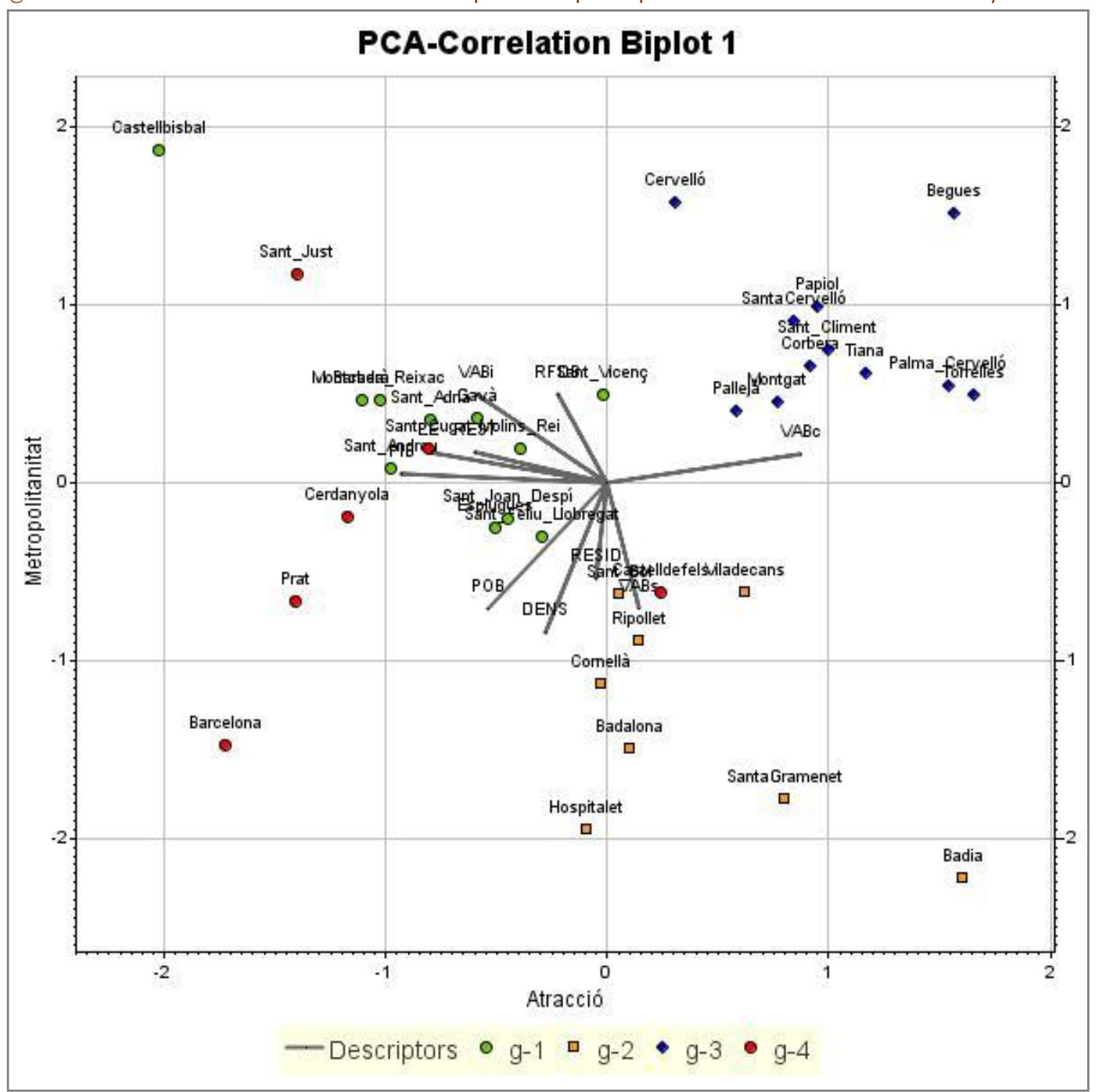

Nota: Els municipis es troben diferenciats d'acord als quatre grups obtinguts amb el mètode d'ordenació kmeans. Font: Elaboració pròpia a partir de les fonts estadístiques vàries citades a l'apartat 2 del present article.

En la Figura 2 s'observen els grups de municipis també amb l'Atracció a l'eix d'abscisses i amb els Sectors económics al d'ordenades. Es distribueixen a l'extrem inferior els municipis més dedicats als serveis i de més elevat poder adquisitiu, i a la part superior els municipis de més baix nivell adquisitiu i més industrials. Així s'observa com el Grup 1 acull els municipis amb un perfil sectorial 
industrial, mentre que el grup 4 integra els municipis menys industrials, i els grups 2 i 3 presenten valors més mixtos per aquest eix.

Figura 2. Gràfic de correlació amb les components principals Pc-1 Atracció o centralitat i Pc-3 Sectors económics

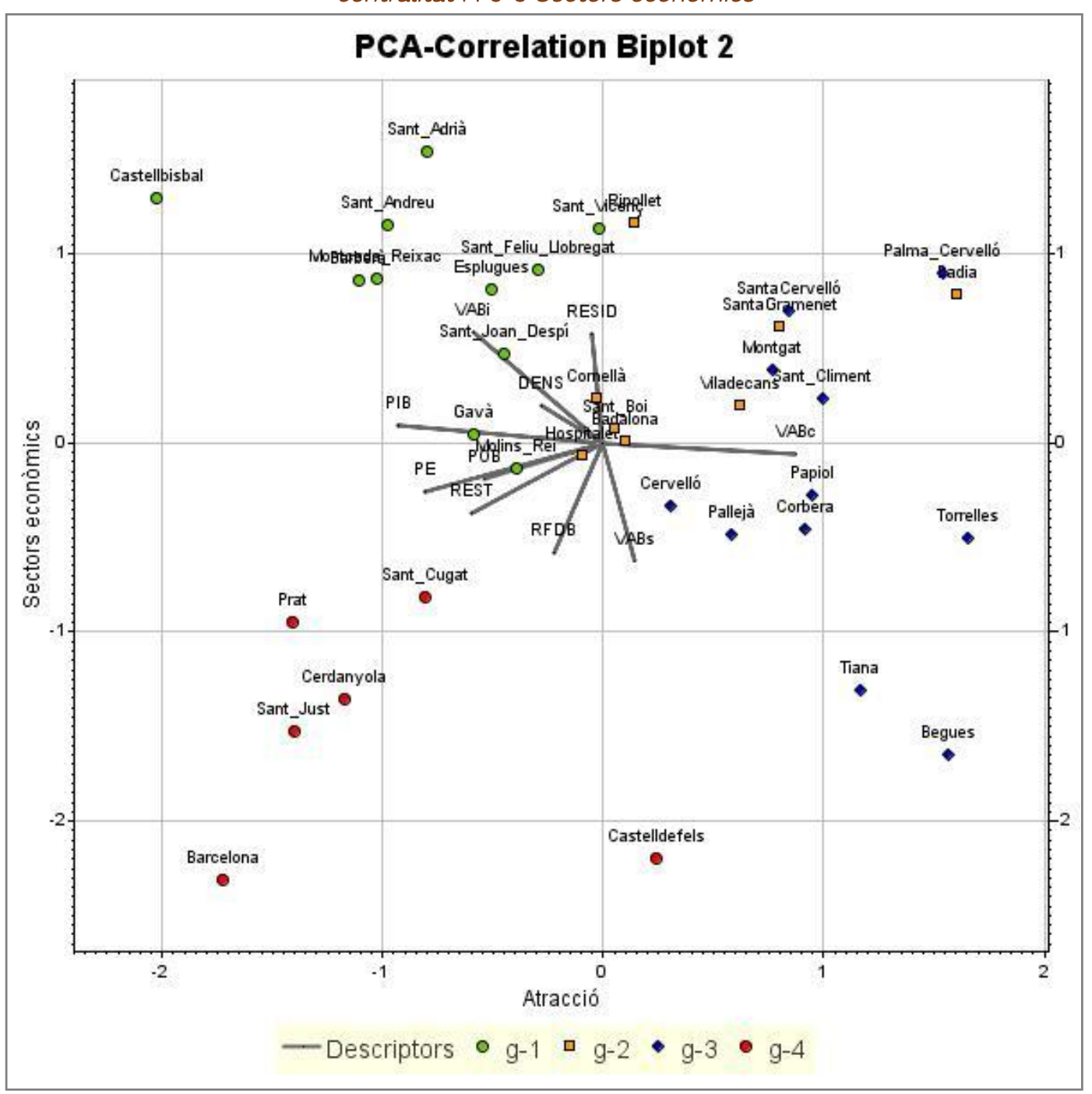

Nota: Els municipis es troben diferenciats pels quatre grups obtinguts amb el mètode d'ordenació k-means. Font: Elaboració pròpia a partir de les fonts estadístiques vàries citades a l'apartat 2 del present article.

En la Figura 3 el perfil sectorial torna a ocupar l'eix d'ordenades i la Metropolitanitat passa a l'eix d'abscisses mostrant, d'esquerra a dreta, municipis que van de més densos i poblats a menys.

En aquest gràfic es torna a observar l'esmentada disposició dels grups d'acord als sectors econòmics però ara front a la Metropolitanitat. Queden a l'esquerra els grups més densos i poblats, Grup 2, i part del Grup 4; a la dreta els menys densos i poblats, Grup 3. El Grup 1, és a dir, el de municipis amb característiques intermèdies queda al mig. 
Figura 3. Gràfic de correlació amb les components principals Pc-2 Metropolitanitat i

Pc-3 Sectors económics

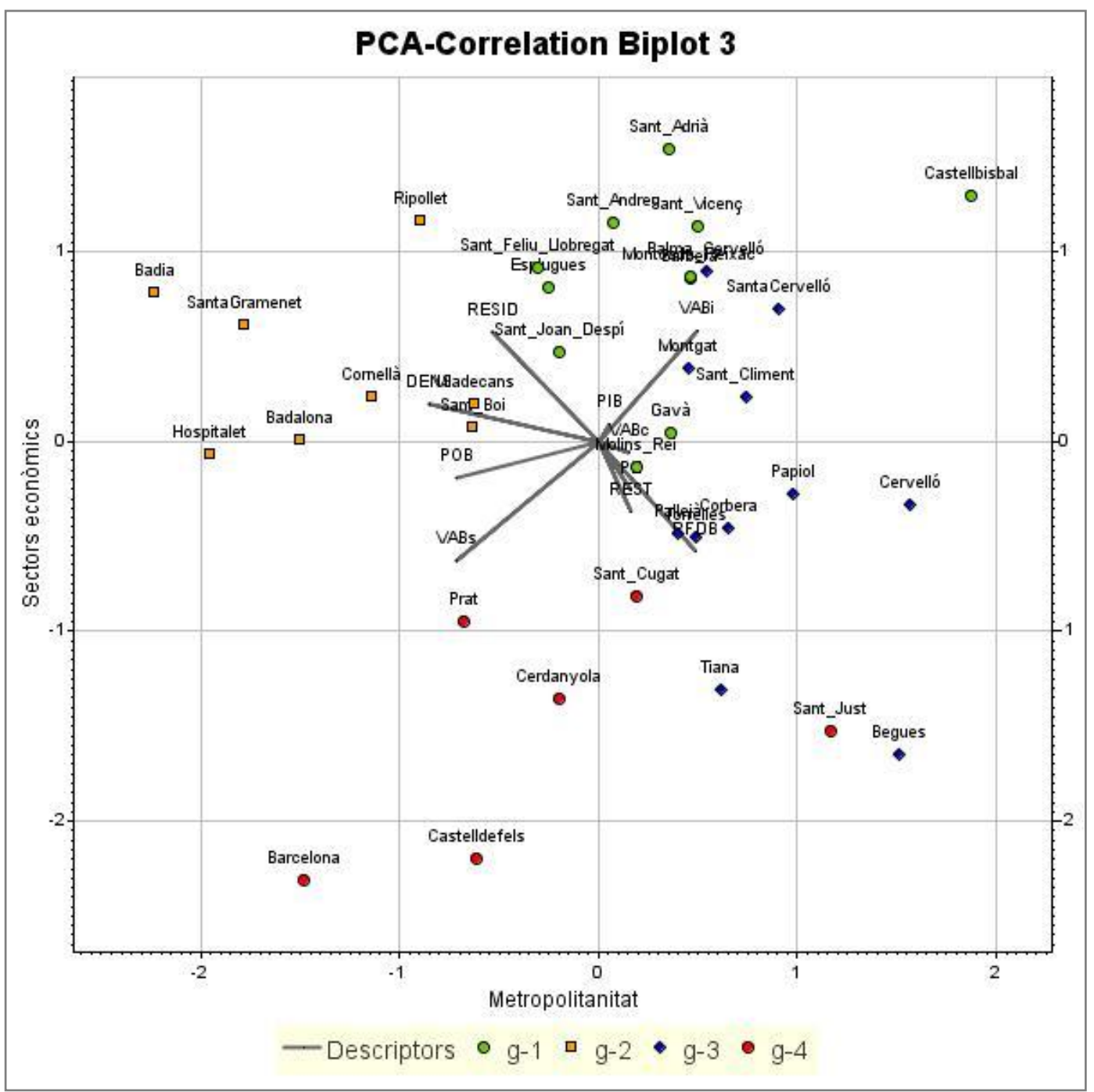

Nota: Els municipis es troben diferenciats pels quatre grups obtinguts amb el mètode d'ordenació k-means. Font: Elaboració pròpia a partir de les fonts estadístiques vàries citades a l'apartat 2 del present article.

\subsection{Estudi de variables socioeconómiques com a indicadors}

Les variables que es relacionen amb la PE del consum de productes manufacturats són, en primer lloc, de tipus econòmic. Els quatre tipus de fonts consultades fan referència a aquestes variables. La influència de les variables econòmiques es fa palesa com a causa determinant de la capacitat de compra de productes de les persones i alhora expliquen moviments de productes entre sectors empresarials. Especialment, la renta de les persones es manifesta com un factor molt decisiu del nivell de despesa de béns manufacturats, demostrant una estreta relació, segons les dades de l'Enquesta de Pressupostos Familiars 2012. Destaca també que aquesta variable s'utilitza en metodologies de càlcul tipus top-down, concretament en les anomenades matrius CLUM.

En segon lloc, figura la generació de residus, que és conseqüència del nivell de consum i, per tant, és indicativa d'aquest. És per aquesta relació directa que s'utilitza en algunes calculadores de PE. 
En tercer lloc, apareix el nombre d'habitants d'una llar, que figura tant en diverses calculadores de PE com a l'Enquesta de Pressupostos Familiars 2012 com a factor relacionat amb el nivell de consum de les persones.

Per altra banda, la mida i densitat d'una població mostren relació amb el nivell de consum de les llars a l'enquesta de pressupostos. Succeeix, doncs, que a ciutats més grans i més denses la població gasta més diners.

Per últim, s'han trobat una sèrie de patrons o hàbits de consum, tant aplicats a les calculadores com explicats per la GFN i discutits a l'estudi de la PE l'àrea metropolitana de San Francisco (Moore i GFN, 2011), que presenten una potent influència en la PE associada al consum de productes. Aquests hàbits són, per exemple, la utilització de productes reciclats, el consum de productes locals, els patrons de renovació de productes, etc.

\section{Discussió}

\subsection{Sobre la caracterització dels municipis}

La caracterització a partir de la classificació qualitativa ha permès assolir un coneixement preliminar dels municipis, que ha revelat una important heterogeneïtat entre ells que fa complexa la seva classificació en grups multivariants. No obstant, s'han trobat patrons de similituds i diferències que poden situar els municipis en diferents pautes de consum de recursos. Per altra banda, s'ha detectat que alguns municipis es poden classificar amb més facilitat, per la proximitat en les seves característiques a d'altres municipis, en canvi d'altres són, en algun o diversos aspectes, marcadament diferents a la resta.

Quant a la caracterització a partir de mètodes estadístics, començant pels resultats de la matriu de correlació de Pearson, la major part dels resultats han coincidit amb els resultats esperables i amb les correlacions trobades a l'anàlisi preliminar, amb l'excepció de la variable Generació de residus domèstics, la qual ha presentat una correlació positiva mitjana amb la Densitat i una correlació negativa mitjana amb la Renda Familiar Disponible Bruta per habitant (RFDB).

En el cas de la correlació amb la densitat, aquesta es podria entendre com un efecte causat pel major consum de productes envasats a les ciutats, mentre que als municipis tipus poble, que són menys densos, els hàbits de consum de les persones tendeixin més a la compra en mercats i botigues de venda de productes directa. Per altra banda, també es pot interpretar considerant l'efecte d'una major abundància d'establiments comercials a les ciutats, els quals aboquen els seus residus a la xarxa de recollida de residus domèstics, fent incrementar d'aquesta manera el volum recollit. Aquestes interpretacions, però, requeririen estudis més exhaustius per comprovar-les.

Quant a la correlació inversa observada entre Generació de residus domèstics i la RFDB trobada, constitueix un fet que contradiu el resultat lògic esperable, que seria un increment de la generació de residus d'acord a majors rendes. Una possible explicació seria que la RFDB es correlaciona negativament amb la Densitat, de tal forma que els municipis més densos tendeixen a ser de menor poder adquisitiu. Per tant, podria ser que la correlació entre les rendes i la generació de residus vingui determinada de forma indirecta per l'efecte de la Densitat, en relació a les possibles causes de l'augment de residus als municipis més densos que s'han explicat a paràgraf anterior. De tota manera, s'hauria de revisar la homogeneïtat de la presa de dades dels residus entre municipis, per tal de descartar possibles biaixos en els valors d'aquesta variable.

ACE, 15 (4:3) CC BY-ND 3.0 ES | UPC Barcelona, España | Aportació metodològica per al càlcul de la Pețjada 
La interpretació conjunta dels resultants de l'anàlisi clúster k-means i de l'anàlisi de components principals ha mostrat l'existència d'unes tipologies de municipis determinades força cohesionades i diferenciades, les quals es pot preveure que presentin patrons de consum de béns manufacturats de diferent rang.

Cal apuntar que en l'estudi de components principals és possible que s'hagi sobrevalorat la component Atracció. Aquesta sobrevaloració seria deguda a que les parelles de variables PIB i Població estacional, i PIB i Valor Afegit Brut de la construcció (totes variables que es relacionen directament o inversa amb aquesta component) aporten, en part, informació redundant (veure Taula 2) i, d'aquesta manera, haurien pogut fer que s'incrementi el pes final d'aquesta component.

\subsection{Sobre la selecció de factors de conversió}

Després d'haver caracteritzat els municipis, s'ha decidit rebutjar la hipòtesi formulada sobre que la PE associada al consum de productes es pot aproximar mitjançant un sol factor de conversió. Acceptar-la suposaria assumir que la proporció entre les importacions i les exportacions es manté constant entre l'àmbit d'estudi superior (Catalunya) i tots els municipis. Per contra, el coneixement dels trets diferencials dels grups ha fet palès que utilitzar un sol factor faria perdre informació i capacitat d'inferència. Remetent-nos a la fórmula càlcul (Galli et al., 2007; Ewing et al., 2010b.) de la PE associada al consum de productes manufacturats:

$$
P E_{\text {consum }}=P E_{\text {importacions }}-P E_{\text {exportacions }}
$$

Disposem de dues variables de signe oposat, la PE associada a les importacions i la PE associada a les exportacions. En relació a això, s'ha considerat que és més consistent que les dues variables siguin inferides no mitjançant un sol factor sinó que a partir de dos, un per a cada incògnita.

És lògic pensar que en el grup Municipis tipus poble, els quals són de caràcter força residencial, no hi ha la mateixa proporció d'exportacions que als Municipis intermedis, els quals presenten una activitat industrial més potent i, per tant, incrementaran la seva capacitat d'exportar productes. D’aquesta manera, el Valor Afegit Brut industrial es postula com a factor de conversió més representatiu per utilitzar per a les exportacions, ja que la capacitat d'exportar vindrà determinada, principalment per les característiques i potència de la indústria dels municipis.

Quant a l'elecció d'un factor de conversió per a les importacions, d'acord a la informació recollida a la fase de recerca documental, les variables que presenten possibilitats de ser bons indicadors del nivell d’importacions són: la Població, la Densitat, la RFDB i la Generació de residus domèstics.

Quant a la Població i la Densitat, es relacionen positivament amb el consum a nivell monetari, segons les dades dels pressupostos familiars de l'INE, però s'han descartat ja que les relacions no són clares a nivell de consum en quantitat de productes. D'una banda, és possible que la població de ciutats més grans i denses gasti més diners en consum de productes a causa de la major oferta, així com per presentar uns hàbits més consumistes. Tanmateix, però, la relació també s'explica pel fet que els productes tendeixen a encarir-se com més poblat i dens és un municipi i, en aquest cas, el consum a nivell de quantitat i massa de productes seria independent. Per tant, la PE no estaria tan relacionada amb aquests factors.

La RFDB s'ha considerat adequada a tenir en compte, ja que té un efecte directe en la despesa i aquesta en el consum final. Altres investigacions han trobat evidències de que se sol establir una relació de proporcionalitat directa entre el nivell de desenvolupament econòmic d'una població i la seva petjada ecològica (Usón, 2012), també un major poder adquisitiu tendeix a anar associat a un

ACE, 15 (4:3) CC BY-ND 3.0 ES | UPC Barcelona, España | Aportació metodològica per al càlcul de la Pețada 
increment de les emissions de $\mathrm{CO}_{2}$ en la mobilitat privada (Soria-Lara et al., 2017). De tota manera, cal aclarir que la relació entre consum a nivell monetari amb el consum de quantitat de productes i la conseqüent PE associada no sempre responen linealment. Això es deu a que un increment en despesa mesurat en unitats econòmiques pot venir donat o bé per un increment en el nombre de productes comprat (de forma que els $\mathrm{kg}$ de productes importats creix) o bé per un increment en els preus dels productes consumits (essent independent als kg de productes importats). Inclús pot succeir que un producte sigui més car per haver estat fabricat en proximitat i, per tant, en alguns casos l'augment en la despesa monetària no es tradueix en un increment del nombre d'importacions ni de la Petjada associada. Per tant, la RFDB no sempre és un bon indicador de l'efecte dels hàbits personals. Una altra limitació és que aquest factor resultaria poc útil per a ser incorporat en programes de reducció de PE dels municipis o Agendes 2030, ja que tindria poc sentit plantejar que la manera per reduir la PE del consum de productes passi per reduir la RFDB mitjana.

Finalment, la variable de Generació de residus domèstics també es considera com a opció amb possibilitats, ja que és una expressió directa del consum final de productes a nivell de particulars. Aquest indicador seria adequat en el sentit que reflecteix els hàbits de consum de les persones i hauria de ser, en aquesta direcció, més complet que la RFDB. De fet, la generació de residus s'ha emprat també com a indicador de l'eficiència del metabolisme urbà i de l'expansió de la petjada ecològica en investigacions sobre urbanisme sostenible (Niño et al., 2019). No obstant, després de les anàlisis efectuades s'ha fet difícil comprendre a quines causes respon el nivell de generació de residus en el context considerat. És per aquest motiu que caldria estudiar a fons com es recullen aquestes dades per a cada municipi i descartar que hi puguin haver biaixos causats per diferències entre municipis en els sistemes de recollida, gestió i/o recompte.

En canvi, la RFDB és una variable tractada de forma homogènia a tota l'AMB, de manera que evitaria el risc explicat d'incorporar biaixos causats en els sistemes de recollida de dades. És per aquest motiu que s'ha triat la RFDB com a factor de conversió del nivell d'importacions de productes manufacturats als municipis l'AMB. Aquest indicador por ser entès com a provisional, mentre s’avanci cap a una millot comprensió de les dades de generació de residus domèstics.

Abans de concloure, s'escau discutir sobre si és o no conseqüent escalar certes variables de la PE quan s'acota tant la resolució espacial. En el cas de les exportacions de béns manufacturats, aquestes responen a models de producció que tenen un abast més gran que la dimensió municipal. Així, un territori de magnitud d'àrea metropolitana presenta una entitat funcional que no es pot atribuir als municipis a nivell independent. Per tant, el més adequat pot ser considerar les exportacions constants a tota l'AMB, però les importacions variables, en funció de la RFDB. Cal tenir present que les importacions depenen del nivell de vida i patró de consum personal que es dugui en un municipi, de manera que aquest factor sí que es pot considerar intrínsec de cada municipi.

L'estudi realitzat ha estat de tipus prospectiu i caldria encetar línies de recerca per tal d'aprofundir en aquest camp, que permetin comprovar quins serien els indicadors més adequats del nivell de consum i comerç de productes manufacturats. Una manera d'avançar cap a l'elecció d'indicadors podria ser una anàlisi estadística basada en un model de regressió múltiple. Per tal de dissenyar el model de regressió, s'haurien de recollir dades de territoris en els quals no hi ha una limitació de disponibilitat sobre els nivells d'importacions i exportacions, i estudiar-ne la relació amb factors que es consideri que poden ser indicatius d'aquests nivells. Llavors es podria comparar com, en variar certs factors entre territoris, varien les variables resposta: els conseqüents nivells d'importacions, per una banda, i exportacions, per l'altra. D'aquesta forma, es contrastaria la influència entre els factors estudiats i la PE associada al consum de béns manufacturats de forma empírica.

ACE, 15 (4:3) CC BY-ND 3.0 ES | UPC Barcelona, España | Aportació metodològica per al càlcul de la Pețjada 


\section{Conclusions}

La caracterització de municipis en grups a partir de diferents metodologies de classificació ha revelat una sèrie de patrons de similituds i diferències que poden situar els municipis en diferents pautes de consum de recursos. Pel que fa als grups obtinguts per mètodes estadístics, la seva formació s'explica en un $77,12 \%$ per tres components principals que reflecteixen: el seu poder d'atracció, el caràcter metropolità i el perfil sectorial dels municipis.

El desenvolupament de la investigació ha portat a rebutjar la hipòtesi plantejada. Així, es conclou que utilitzar un sol factor de conversió per tal d'estimar la PE associada al consum de béns manufacturats faria perdre molta informació i en calen dos: un per tal d'estimar les importacions i un altre per a les exportacions.

Com a factor més adequat per estimar les importacions de productes en el context dels municipis de l'AMB, es proposa la RFDB, ja que s'ha comprovat que presenta una relació directa amb el nivell d'adquisició de productes manufacturats. No obstant, caldria aprofundir en la comprensió de la variable de generació de residus, que podria arribar a ser un factor de conversió més adequat, ja que inclou els efectes dels hàbits de consum més o menys sostenibles, poc reflectits amb la RFDB.

Com a factor més adequat per estimar les exportacions de productes als municipis de l'AMB es proposa el Valor Afegit Brut industrial, per ser el factor que millor s'hi relaciona. No obstant, es planteja la possibilitat de mantenir les importacions com a variable fixa a tota l'AMB. Cal tenir en compte que un territori de magnitud d'àrea metropolitana presenta una entitat funcional a nivell de producció i exportacions que no és atribuïble als municipis a independentment, a diferència de les importacions, que depenen dels patrons de consum personals que ocorren a cada municipi.

Cal remarcar l'interès dels estudis de la PE a nivell municipal com una eina per assessorar de manera integrada polítiques ambientals i de sostenibilitat ja que aquest macroindicador copsa àmpliament el nivell d'impactes que una població exerceix sobre els ecosistemes per tal de mantenir el seu nivell de vida i, alhora, permet aproximar quin és el nivell de PE que seria assumible en un model sostenible.

Les estimacions de PE poden servir per fixar objectius ambientals municipals enfocades a reduir l'impacte sobre les diferents variables de càlcul del macroindicador, i definir estratègies de millora per tal d'assolir-los. És per això que la importància de calcular la PE a nivell municipal va més enllà d'obtenir-ne el valor i analitzar-lo, prenent sentit el seu càlcul periòdic, per tal d'avaluar el compliment de les polítiques municipals engegades.

\section{Autoria}

La primera autora va ser autora de la tesina de màster de la qual deriva aquest article i el segon autor va ser el seu tutor. Tots dos autors van conceptualitzar la recerca i van definir l'estructura del treball. La primera autora ha escrit l'article i el segon autor ha fet la revisió general. Tos dos han discutit i elaborat les conclusions.

Conflicte d'interessos: Els autors declaren que no hi ha conflicte d'interessos. 


\section{Bibliografia}

Ajuntament de Santa Coloma de Gramenet i Diputació de Barcelona. (2005). Hàbits de compra. Observatori de comerç de Santa Coloma. Recuperat de http://www.grame.net/fileadmin/Files/Ajuntament/comercio/eng habits.pdf

Àrea Metropolitana de Barcelona (AMB). (2014-2020). Catàleg de dades obertes. Recuperat de http://www.amb.cat/web/area-metropolitana/dades-obertes/cataleg/llistat//dataset/categories/medi ambient

Carreras, J.M.; Otero, M.; Ruíz, E. (2013). L'ocupació del territori a l'Ảrea i Regió Metropolitana de Barcelona 1956-2006. Barcelona, Espanya: Àrea Metropolitana de Barcelona.

Center for Sustainable Economy. (2014). Climate Action Network International. Recuperat de http://www.climatenetwork.org/profile/member/center-sustainable-economy

Diputació de Barcelona (DIBA) (2014-2020). Dades obertes. Recuperat de https://dadesobertes.diba.cat/

Environment Protection Authority (EPA) of Victoria, Australia (2005) EPA Ecological Footprint Calculators: Technical background paper. Recuperat de https://www.epa.vic.gov.au//media/epa/files/publications/972.pdf

Ewing, B. et al., Global Footprint Network. (2010a). Ecological Footprint Atlas. Recuperat de http://www.footprintnetwork.org/images/uploads/Ecological Footprint Atlas 2010.pdf

Ewing B. et al., Global Footprint Network. (2010b). Calculation Methodology for the National Footprint Accounts. Recuperat de http://www.footprintnetwork.org/images/uploads/National Footprint Accounts Method Paper 2010 .$p d f$

Fenga, K. et al. (2010). Comparison of bottom-up and top down approaches to calculating the wàter footprints of nations. Economy Systems Research, 23(4), 371-385.

Forman, R.T.T., Barcelona Regional. (2004). Mosaico territorial para la planificación de la Regió Metropolitana de Barcelona. Barcelona, Espanya: Editorial Gustavo Gili SA.

Galli, A.; Kitzes, J.; Wermer, P.; Wackernagel, M.; Niccolucci, V.; Tiezzi, E., (2007). An exploration of the mathematics behind the ecological footprint. International Journal of Ecodynamics, 2(4), 250-257. Recuperat de http://http://www.witpress.com/elibrary/wit-transactions-on-state-of-the-art-inscience-and-engineering/51/22869

Galli, A.; Wiedmann, T.; Ercin, E.; Knoblauch, D.; Ewing, B.; Giljumf, S. (2012). Integrating Ecological, Carbon and Water footprint into a "Footprint Family" of indicators: Definitionandrole in tracking human pressure on the planet. Ecological Indicators. 16, 100-112. DOI: https://doi.org/10.1016/j.ecolind.2011.06.017

Global Footprint Network. (2009). Ecological Footprint Standards 2009. Recuperat de http://www.footprintstandards.org

Global Footprint Network (GFN) (2014-2020). Footprint calculator. Recuperat de https://www.footprintnetwork.org/resources/footprint-calculator/

Gullón, N.; Esteban, F. (2008). Análisis de la Huella Ecológica de España. 2008. Madrid, Espanya: Ministerio de Medio Ambiente, Medio Rural y Marino.

ACE, 15 (13) CC BY-ND 3.0 ES | UPC Barcelona, España | Aportació metodològica per al càlcul de la Petjada 
Institut d'Estadística de Catalunya, Generalitat de Calalunya. (2012). Anuari estadístic de Catalunya 2012. Recuperat de https://www.idescat.cat/pub/?id=aec

Institut d'Estadística de Catalunya, Generalitat de Calalunya. (2013-2020). El municipi en xifres. Recuperat de https://www.idescat.cat/emex/

Institut d'Estadística de Catalunya, Generalitat de Calalunya. (2013-2020). Estadística d'establiments turístics. Recuperat de https://www.idescat.cat/pub/?id=turall

Institut d'Estadística de Catalunya, Generalitat de Calalunya. (2013-2020). Ampliació de resultats de la mobilitat obligada. Recuperat de http://www.idescat.cat/mobilitat/?n=1\&t=2001

Instituto Nacional de Estadística. (2013-2020) Encuesta de presupuestos familiares. Recuperat de https://www.ine.es/dyngs/INEbase/es/operacion.htm?c=Estadistica C\&cid=1254736176806\&menu=ul tiDatos\&idp $=1254735976608$

Mayor, X. (2006). Petjada Ecològica, consum del territori com a recurs? L'atzavara, 17: 13-21. Recuperat de https://core.ac.uk/reader/39059972

Mayor, X.; Quintana V. i Belmonte, R. (2005). Aproximació a la Petjada Ecológica de Catalunya. Barcelona, Espanya: Generalitat de Catalunya, Consell Assessor per al Desenvolupament Sostenible.

Mayor, X.; Torres, A. i Barba, J. (2006). Estudi sobre la Petjada Ecológica de Catalunya i el seguiment de la participació de Catalunya en la Xarxa Global de Petjada Ecológica. Barcelona, Espanya: Generalitat de Catalunya, Departament de medi ambient i habitatge.

Mayor, X. et al. (2013). Càlcul de la Petjada Ecológica de l'Área Metropolitana de Barcelona i desenvolupament d'un mètode estàndard per al càlcul municipal. Barcelona, Espanya: Barcelona Regional: Agencia de desenvolupament urbà.

Miliarium.com Ingeniería civil y Medio ambiente. Calculadora de huella ecológica. Recuperat de www.miliarium.com/formularios/huellaecologicaa.asp

Miller, T. (1994). Ecología y medio ambiente. México DF, México: Ed. Iberoamericana.

Ministerio de Medio Ambiente y Medio rural y marino, Gobierno de España. (2007). Análisis de la huella ecológica de España. I.S.B.N.: 978-84-491-0913-3. Recuperat de https://www.footprintnetwork.org/content/images/uploads/Huella\%20ecologica\%20de\%20Espana.pdf

Monfreda, C.; Wackernagel, M. i Deumling, M. (2004). Establishing national natural capital accounts based on detailed Ecological Footprint and biological capacity assessments. Land Use Policy. 21(3), 231-246. DOI: https://doi.org/10.1016/j.landusepol.2003.10.009

Moore, D. et al., Global Footprint Network. (2013). Methodology for Calculating the Ecological Footprint of California. Recuperat de https://www.footprintnetwork.org/content/images/article uplo ads/EcologicalFootprintCalifornia Method 2013.pdf

Moore, D., Global Footprint Network. (2011). Ecological Footprint analysis San Francisco-OaklandFremont, CA. Recuperat

http://www.footprintnetwork.org/images/uploads/SF Ecological Footprint Analysis.pdf

Moore, D. i Stechbart, M. (2011). Huella ecológica de Quito. Quito, Ecuador: Municipio del Distrito Metropolitano de Quito, Ecuador.

Niño, A. S.; Badillo, W. L.; Dávila, M. (2019). Indicadores urbanos como instrumento de análisis para el diseño de proyectos de espacio público. ACE: Architecture, City and Environment, 13(39), 75-104. DOI: http://dx.doi.org/10.5821/ace.13.39.5366

ACE, 15 (4:3) CC BY-ND 3.0 ES | UPC Barcelona, España | Aportació metodològica per al càlcul de la Pețjada 
Organización de consumidores y usuarios (OCU) Calculadora de huella ecológica. Recuperat de http://www.ocu.org/vivienda-y-energia/agua/calculadora/consultor-ecologico

Provincia di Genova. (2005). Impronta ecológica della provincia di Genova. Recuperat de http://www.provincia.genova.it/servlets/resources?contentld=18087\&resourceName=Allegato-pdf

Relea, F. i Prat, A. (1998). La Petjada Ecológica de Barcelona. Una aproximació. Barcelona, Espanya: Comissió de Medi Ambient i Serveis Urbans, Ajuntament de Barcelona.

Soria-Lara, J. A.; Miralles-Guasch, C.; Marquet, O. (2017). The influence of lifestyle and built environment factors on transport $\mathrm{CO}_{2}$ emissions: the case study of Autonomous University of Barcelona. ACE: Architecture, City and Environment, 12(34), 11-28. DOI: http://dx.doi.org/10.5821/ace.12.34.4756

Stechbart, M.; Wilson, J. i Global Footprint Network. (2010). Province of Ontario. Ecological Footprint and Biocapacity Analysis. Recuperat de http://www.footprintnetwork.org/images/uploads/Ontario Ecological Footprint and biocapacity TECHNICAL report.pdf

Subirats, J.; Font, N. i Riba, C. (2002). Enquesta d'Hàbits i Valors sobre Medi ambient i Sostenibilitat. Ajuntament de Barcelona, Institut de Govern i Polítiques Públiques (UAB). Recuperat de https://bcnroc.ajuntament.barcelona.cat/jspui/bitstream/11703/89062/1/10590.pdf

Subirats, J.; Font, N. i Riba, C. (2010). Enquesta d'Hàbits i Valors sobre Medi ambient i Sostenibilitat 2007. Ajuntament de Barcelona, Institut de Govern i Polítiques Públiques (UAB). Recuperat de https://bcnroc.ajuntament.barcelona.cat/jspui/bitstream/11703/89063/1/10593.pdf

Tarragó, M. et al. (2012). Estudi dels hàbits de compra i els fluxos d'atractivitat de les polaritats comercials a la ciutat de Barcelona. Barcelona, Espanya: Ajuntament de Barcelona, Àrea d’Economia, Empresa i Ocupació, Direcció de Comerç i Consum.

The City of Calgary. (2007). Toward a Preferred Future. Understanding Calgary's Ecological Footprint. Recuperat de http://www.footprintnetwork.org/images/uploads/Calgary Ecological Footprint Report.pdf

Trullén, J.; Porcel, S. i Fernández, M. (2012). Enquesta de condicions de vida i hàbits de la població de Catalunya. Diputació de Barcelona, Institut d'Estudis Regionals i Metropolitans de Barcelona, Àrea Metropolitana de Barcelona. Recuperat de http://www1.diba.cat/llibreria///stDetall Publicacions.asp?Opener=Libreria\&ID=53825

Usón Guardiola, E. (2012). Estrategias para la reducción del impacto ambiental en los nuevos desarrollos urbanos: ejemplo de aplicación. ACE: Architecture, City and Environment, 7(19), 55-76. DOI: http://dx.doi.org/10.5821/ace.v7i19.2561

Wackernagel, M. i Rees W. (1996). Our Ecological Footprint. Reducting Human Impact on the Earth, Canada: New Society Publishers.

Wackernagel, M.; Monfreda, C; Moran, D.; Wermer, P.; Goldfinger, S.; Deumling, D.; Murray, M. (2004). National Footprint and Biocapacity Accounts 2005: The underlying calculation method. Land Use Policy. 21.

Wackernagel, M.; Onisto, L.; Bello, P.; Callejas Linares, A.; López Falfán, I.S.; Méndez García, J.; Suárez Guerrero, A.I. i Suárez Guerrero, M.G. (1999a). National natural capital Accounting with the Ecological Footprint concept. Ecological Economics, 29(3), 375-390. DOI: https://doi.org/10.1016/S0921$\underline{8009(98) 90063-5}$

World Wildlife Fundation (WWF). (2013-2020) Footprint calculator. Recuperat de http://footprint.wwf.org.uk/ 